\title{
El Norte Grande durante el Ciclo del Salitre: \\ LA POLÍTICA SALITRERA Y LA POLÍTICA EXTERIOR EN LA \\ FORMACIÓN DE UN ESPACIO TRANSFRONTERIZO \\ (Bolivia y Chile, 1880-1929) ${ }^{1}$
}

\author{
Sergio González Miranda y Sandra Leiva Gómez
}

\begin{abstract}
Resumen
Aquí se sostiene que la construcción social y administrativa del Norte Grande estaría relacionada con la política salitrera y con la política exterior de Chile después de la Guerra del Pacífico. Se plantea una hipótesis sobre la importancia del "impuesto al salitre" (1880) como el inicio de la construcción social de espacio transfronterizo. En este trabajo se analizan ambas políticas públicas que, en una primera etapa -entre 1880 y 1904-, habrían coincidido al permitir que regiones transfronterizas se relacionaran con la industria salitrera a través de circuitos de bienes y personas. En dicho período, el Estado chileno habría desarrollado su "política boliviana" de distención con ese país y habría tenido un papel económico de Estado rentista y políticamente ausente de las regiones salitreras. Entre 1904 y 1929 , esos papeles cambiarían por otros más activos, donde las diplomacias de Bolivia y Chile inician sus litigios y las fronteras en transición se endurecen hasta conformar los límites internacionales actuales del Norte Grande
\end{abstract} de Chile.

Palabras claves: política salitrera - política exterior - empresariado minero - diplomacia.

\begin{abstract}
It is said here that the social and organizational creation of the Big North would be related to the politics of saltpetre and foreign policy of Chile after the War of the Pacific. A hypothesis is suggested about how important the "saltpetre tax" is (1880) as the beginning of the social construction of cross-border space. In this work both public policies are analysed that, during the first period between 1880 and 1904 would agree to allow the cross-border regions to be related to the saltpetre industry through the circuit of goods and people. In that period the Chilean state would develop its "Bolivian policy" of detente with that country and would have an economic role of rentier state and politically out of the saltpetre regions. Between 1904 and 1929 those roles would be changed by more active ones, where the diplomacies of Bolivia and Chile start their law suits and the borders in transition are made stricter to make up the current international borders of the Big North of Chile.
\end{abstract}

Key words: politics of saltpeter - foreign policy - mining business sector - diplomacy.

Recibido: octubre 2015. Aceptado: enero 2016.
“Cuando llegué de Bolivia el año 23, a los 13 años. En 1923 llegamos de Bolivia, ahí empecé a trabajar de matasapos en la oficina Aurora. Después ahí ya empecé a trabajar de carrilano. Ganaba 5,50 pesos..." (Basilio Osinaga, pampino salitrero $)^{4}$.

\section{El Norte Grande de Chile}

En Chile, al referirse al desierto, inmediatamente se piensa en Atacama, a pesar de que en la Patagonia existe una región que puede ser también definida como un desierto. Del mismo modo, si se menciona a la minería, surge la imagen de Atacama, aunque en regiones como Rancagua o Bío-Bío han existido - y existen - importantes explotaciones mineras de cobre y carbón. Todas esas imágenes, por metonimia, se asocian además al campo semántico y al espacio geográfico que ocupa el Norte Grande de Chile.

La importancia del nombre "Norte Grande" — que los habitantes le dieron a la parte del desierto de Atacama al norte de Taltal - está en la dimensión cultural. En efecto, como lo afirman Gilberto Giménez y Catherine Héau Lambert, siguiendo a Bonnemaison:

"La apropiación del espacio, sobre todo cuando predomi

1 Este artículo exhibe parte de los resultados del Proyecto Anillo SOC 1109 . Los autores, investigadores titulares del proyecto, agradecen a CONICYT su financiamiento y colaboración.

2 Instituto de Estudios Internacionales, Universidad Arturo Prat, Av. Arturo Prat 2120, código postal 1110939, Iquique, Chile, pampino50@gmail.com.

3 Instituto de Estudios Internacionales, Universidad Arturo Prat, Av. Arturo Prat 2120, código postal 1110939, Iquique, Chile, sandleiva@gmail.com.

4 Archivo Hombres y Mujeres de la Pampa. 
na la dimensión cultural, puede engendrar un sentimiento de pertenencia que adquiere la forma de una relación de esencia afectiva, e incluso amorosa, con el territorio. En este caso el territorio se convierte en un espacio de identidad o, si se prefiere, de identificación, y puede definirse como "una unidad de arraigo constitutiva de identidad" (2007: 12).

La identidad "pampina" fue la que surgió del desierto durante la industria del salitre y que se extendió durante el período del cobre, dos ciclos que fueron consecutivos, pues cuando la economía del nitrato de soda comenzaba su decadencia definitiva hacia el término de la Primera Guerra Mundial, la economía del cobre iniciaba su expansión. A pesar de la importancia de la identidad pampina, su referente - la pampa - era una categoría que no permitía imaginar todo el territorio comprendido en los límites fronterizos con Perú y Bolivia, donde existen zonas que no son "pampas". En cambio, la categoría "Norte
Grande", a pesar de haber surgido desde el habla ordinaria (en el sentido de Dilthey [López Molina 2008]) de los habitantes del desierto de Atacama, permitió distinguir un territorio amplio, enmarcado entre las fronteras de Chile con Perú y Bolivia y la frontera interior de Taltal (Ver Figura 1, donde se observa al Norte Grande de Chile hacia 1909, en pleno auge de la economía del salitre, donde se incluyen a las provincias de Tacna y Arica que estaban en litigio entre Perú y Chile).

Por lo anterior, el Norte Grande de Chile es la referencia obligada cuando se estudian las relaciones vecinales de Chile con Perú y Bolivia (y también con el noroeste de Argentina); también lo es cuando se analizan los flujos de bienes y personas que circularon a través de esas fronteras desde y hacia los cantones salitreros.

El Norte Grande de Chile, en el siglo diecinueve, fue entonces sinónimo de desierto y de minería salitrera, pero

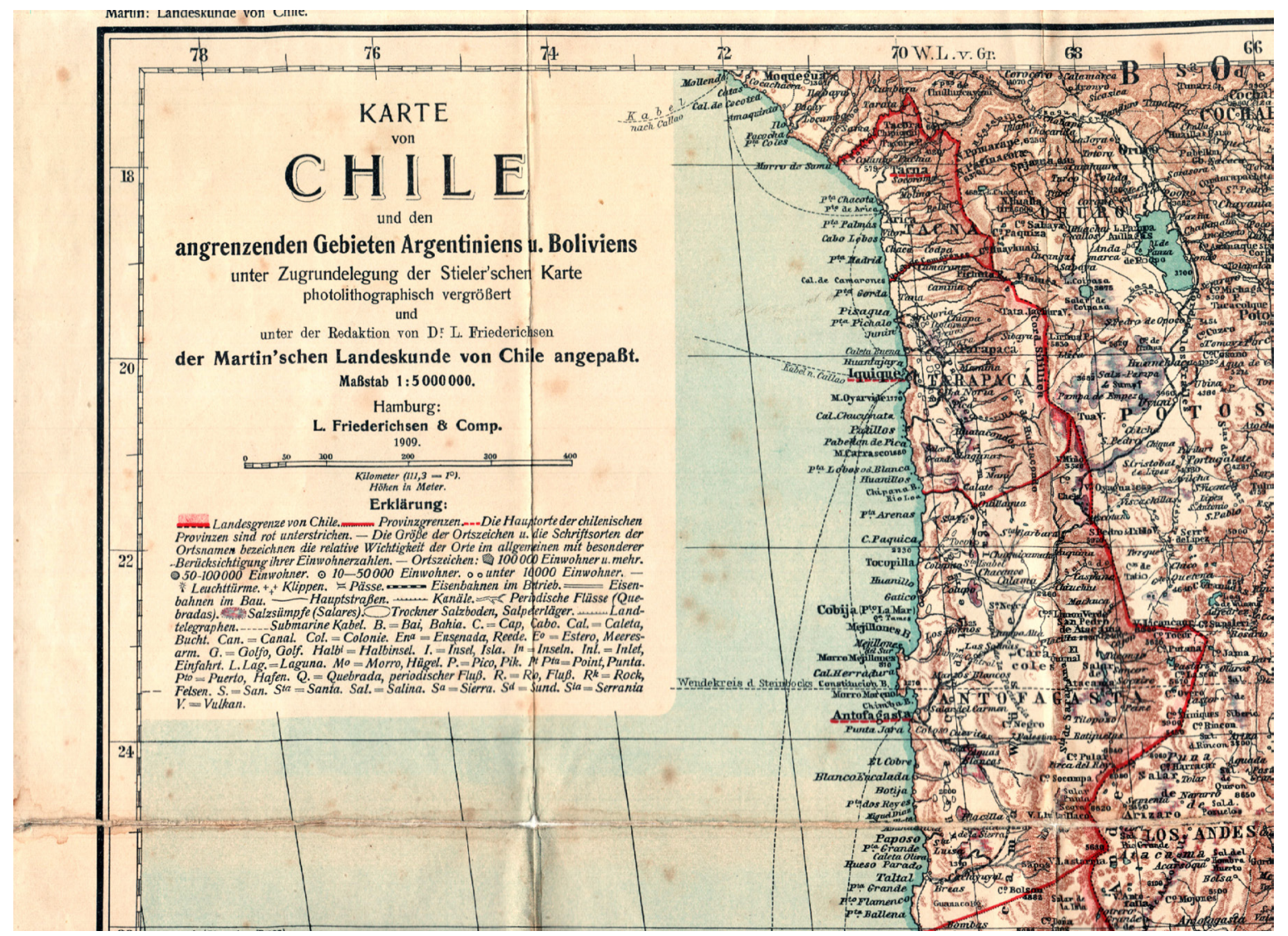

Figura 1. Provincias de Tacna, Tarapacá y Antofagasta en pleno auge del ciclo del salitre. Fuente: V.C. Martin, Chile y las zonas adyacentes de Argentina y Bolivia. Imprenta L. Friederichsen y Compañía, Hamburgo, 1909. 
también está asociado a la Guerra del Pacífico. Una simplificada síntesis del fenómeno que dio origen al Norte Grande, nos la entrega Michael Monteón:

En los 1870 , los chilenos se trasladaron al Desierto de Atacama, a lugares de propiedad de Bolivia y Perú que exportaban salitre. A fines de la década, Bolivia, Chile y Perú recurrieron a estos depósitos de salitre para compensar las consecuencias de la recesión financiera en la economía del Atlántico. El resultado de esta competencia fue la Guerra del Pacífico (1879-83), en la cual Chile conquistó las provincias salitreras, tomando Antofagasta de Bolivia y Tarapacá de Perú. El salitre, utilizado como fertilizante o para hacer pólvora, hizo que Chile fuera la piedra angular de la economía a comienzos de los 1920s (1998:16).

En rigor, los chilenos que se trasladaron hacia el desierto de Atacama llegaron primero al cantón de Taltal, que siempre fue chileno. Efectivamente, los tres países compartieron los mismos intereses económicos al explotar los mantos de caliche de Tarapacá y Antofagasta. Por tanto, la colisión entre ellos tenía alta probabilidad de producirse. Chile, en la década de 1920, en realidad ya no era la piedra angular de la economía salitrera, pues comenzaba su pérdida de competitividad en el mercado internacional de los fertilizantes.

En esta cita, Monteón relaciona la Guerra del Pacífico -que involucró a Perú, Bolivia y Chile - con la industrialización del salitre, pero no profundiza en el efecto que ese conflicto y esa economía generó en las relaciones vecinales de los tres países a partir de 1884. Francisco Zapata aborda parcialmente esas relaciones desde una perspectiva histórico sociológica y no desde el campo de las relaciones internacionales, empero, es una primera aproximación que abarca los ciclos del salitre y del cobre relacionándolos con los hitos diplomáticos entre estos tres países (Zapata 1992).

Siguiendo la argumentación anterior, la primera frontera que enmarcó lo que sería el Norte Grande de Chile fue la ubicada en Taltal ( $\left.25^{\circ} 30^{\prime} \mathrm{S}\right)$. Durante el período colonial se mencionaba a Paposo ( $25^{\circ} \mathrm{O}$ ' S) como frontera entre Perú, Bolivia y Chile (Paz Soldán 1878), localidad ubicada al norte de Taltal, aunque hay autores que la cuestionan señalando al río Loa como la frontera colonial entre ambos países (Eyzaguirre 1963). Para las siguientes fronteras (con Perú y Bolivia) se puede afirmar que, a partir de 1884, quedaron "en transición" pues los tratados bilaterales, como los pactos de guerra, no las establecieron de modo definitivo. Recién con el Tratado de Paz y Amistad de 1904 entre Bolivia y Chile, se definió esa frontera internacional; igualmente entre Perú y Chile fue el Tratado de Paz y Amistad de 1929, el que estableció la Línea de la Concordia.

Esta condición fronteriza "en transición", sostenemos, permitió la consolidación de un "espacio trasfronterizo salitrero" que se asemeja más al "espacio peruano colonial" de la economía argentífera - cuyo centro productivo estaba en Potosí, Bolivia, descrito por Carlos Sempat Assadourian (1982) - que a las modernas fronteras de los estados nacionales del siglo veinte.

Lo anterior se explica mejor aún al constatar una ausencia del Estado nación chileno en el control fronterizo durante el ciclo de expansión del salitre (Castro 2008) y por la existencia de una política salitrera que deja en manos de los empresarios la administración de esta industria. Por lo anterior, sostenemos que la política salitrera chilena, que optó por la aplicación de un impuesto alto y la libertad empresarial, versus la política salitrera peruana, de mayor intervención gubernamental en beneficio de un grupo nacional de empresarios (González 2014), fue clave para que las fronteras no fueran un obstáculo para los flujos de bienes y personas que la industria del nitrato requería. De tal modo, el Norte Grande de Chile surgió más por la ausencia de una política pública de ordenamiento territorial que por una geopolítica nacional sobre un territorio estratégico.

El concepto "Norte Grande" permitió identificar una macrozona desde donde fue posible estructurar un "espacio transfronterizo". En ese espacio, los cantones salitreros y las diversas oficinas eran pequeños polos de atracción para los enganches de trabajadores y los flujos de mercancías (Figuras 2 y 3). A continuación, un extracto de la entrevista al señor Basilio Osinaga, pampino de origen boliviano:

\section{"E: Dígame, ¿sus papás eran pampinos?}

SR. OSINAGA: No mis papás fueron bolivianos se vinieron muy jóvenes y de ahí ya también anduve pa' Bolivia en la crisis, en la guerra del 14, del 18. Yo me acuerdo la primera vez yo tenía como 9 años cuando fui a Bolivia. La segunda vez cuando fue la crisis, 


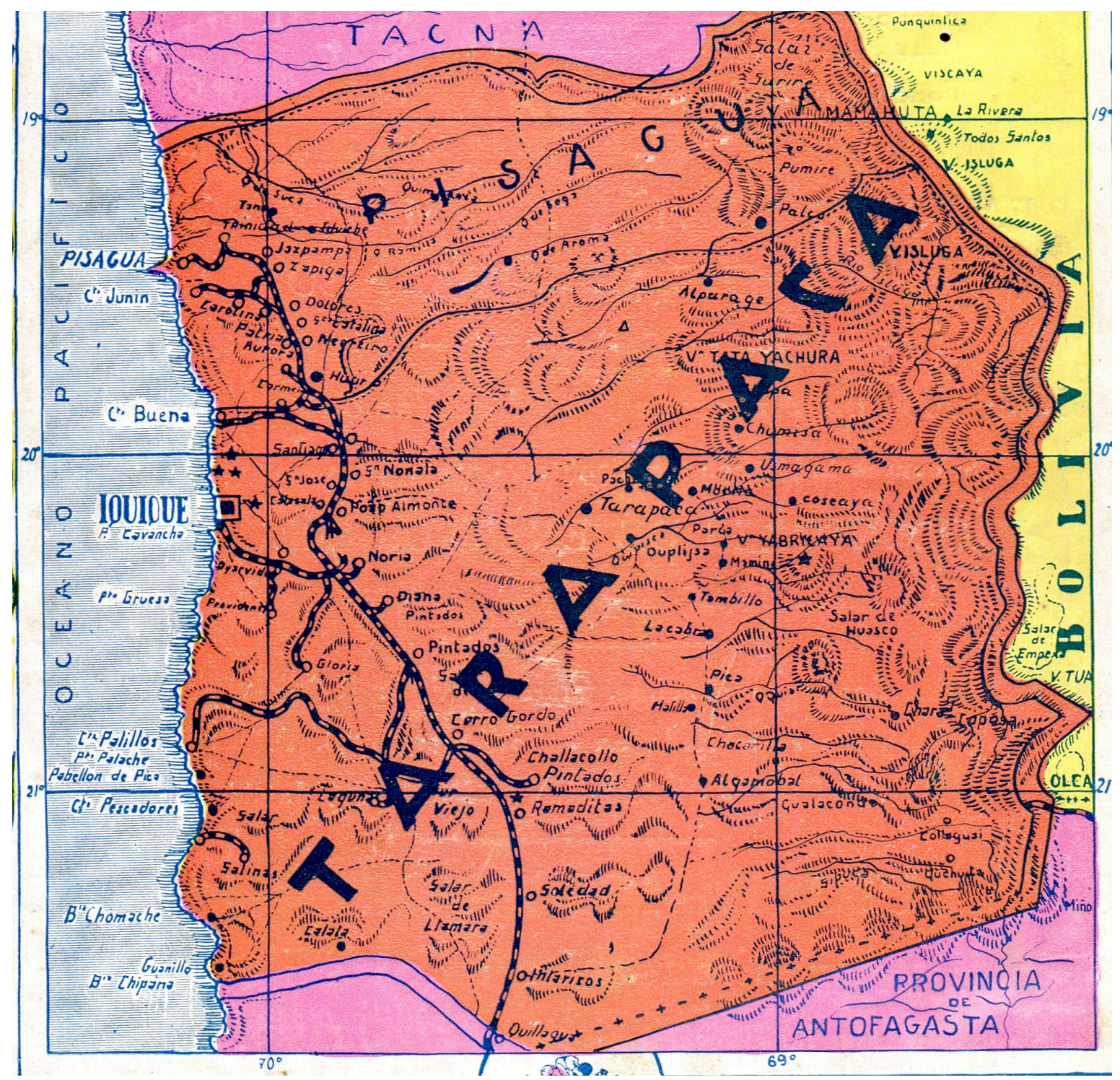

Figura 2. Tarapacá Salitrero. Fuente: Chile. Boletín Consular del Ministerio de Relaciones Exteriores, Vol. III, Febrero de 1927 , (Portada). Imprenta Universo, Santiago.

yo tenía como 10 años, fue el año 20.

\section{E: ¿Usted fue a trabajar en las minas allá?}

SR. OSINAGA: No, fui bien chiquillo, fui de 10 años. De ahí volví por el año 23. De ahíya.

E: ¿Dónde nació el papá?, ¿de Bolivia de qué parte?

SR. OSINAGA: Cochabamba

E: ¿Y se vinieron a buscar trabajo aquí?, ¿nuevos horizontes?

SR. OSINAGA: Claro y por ejemplo la primera vez que volvieron para allá. Claro que yo más o menos de eso me di cuenta porque la vida es muy distinta de la de la pampa. Porque en la pampa en ese tiempo digamos no sería tan bueno, no habría tanto adelanto pero se vivía mejor. Lo más importante era que trabajo no faltaba. No era un problema el trabajar, estando en tiempo normal. No se preocupaba uno, no tenía ningún problema.

\section{E: ¿Se iban a otra oficina no más?}

SR. OSINAGA: Irse a otra oficina, no tenía monos, sino que lo que pescaba más a mano. Se llevaba todo y sabía que iba a traba 


\section{PLANO DE SITUACION Oficinas Salitreras} DE ANTOFAGASTA

Con relacion a los Ferrocarriles y Puertos de Embarque

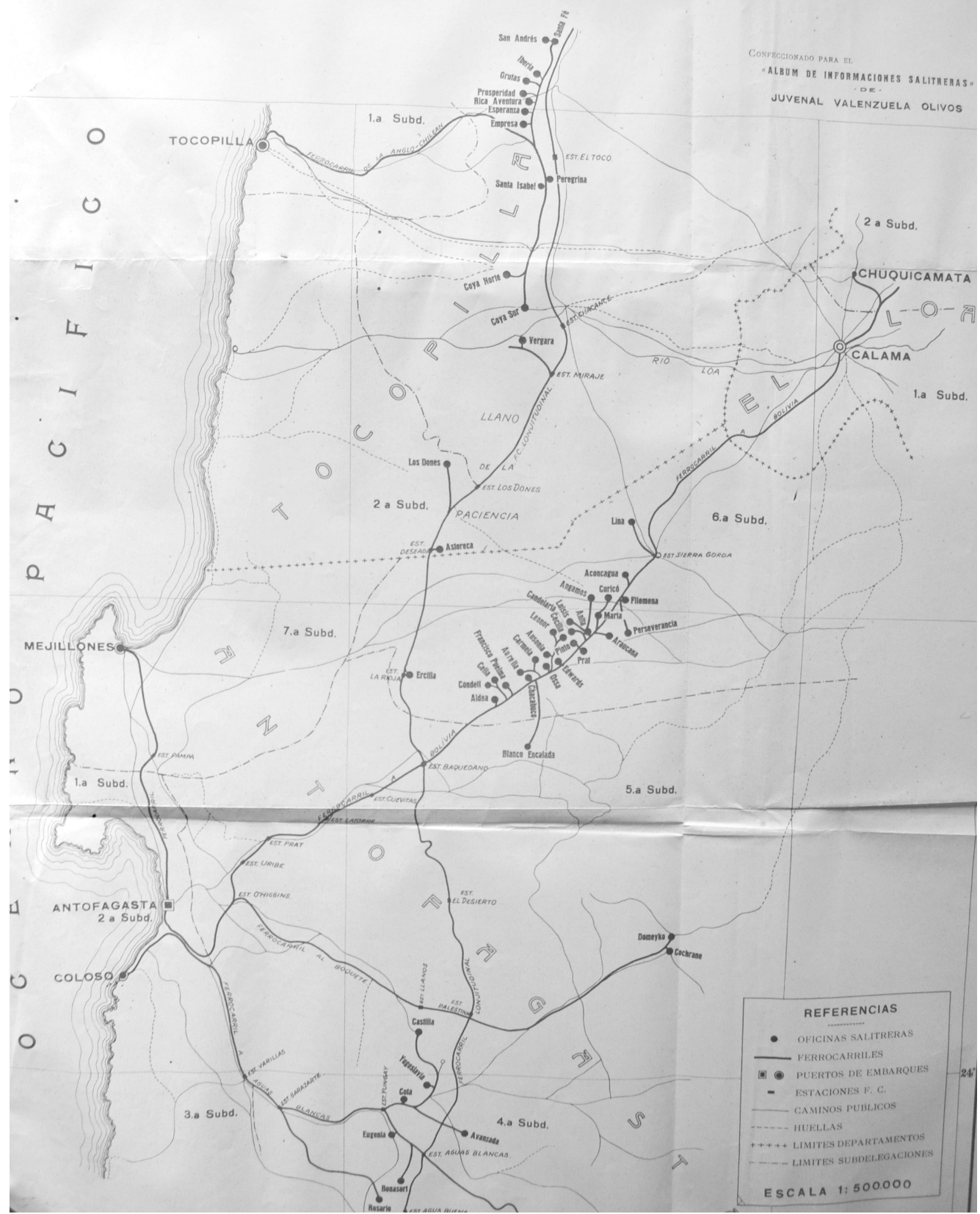

Figura 3. Antofagasta Salitrero. Fuente: Álbum Informaciones Salitreras Agrícolas i Comerciales. Zona Norte de Chile. Editor: Juvenal Valenzuela O. Imprenta Universidad, Santiago, 1927, p. 70. 
jar al tiro. Asíque por esa razón, la gente que llegaba de cualquier parte, tanto del sur como de Bolivia, ya no se acostumbrab a a volver a lo de antes, porque yo ya me di cuenta cuando fui a trabajar a Bolivia, más esclavizada la vida. Aquí habiendo trabajo no tenía ningún problema, yo creo que para el Sur, para el campo debe pasar lo mismo, me imagino. Más sometido, más esclavizada la vida y en la pampa no, había libertad para todo, había trabajo y habiendo trabajo, usted sabe que....

E: ¿Su papá de qué trabajada en la pampa?

SR. OSINAGA: De particular. Mi papá fue particular, yo trabajé de llenador de carros. Más entréla canchay de particular trabajé toda mi vida, fue muy poco en la máquinas, más de particular.

\section{E: ¿Sus papás se vinieron casados de Bolivia?}

SR. OSINAGA: Casados con mi mamá.

\section{E: ¿Ya tenían algunos hijos?}

SR. OSINAGA: Una hermana o dos. Después todos los demás en Chile.

\section{E: ¿En la pampa? \\ SR. OSINAGA: En la pampa.}

\section{E: ¿Usted nació en (la oficina salitrera) Rosario? \\ SR. OSINAGA: iEn Rosario de Huara!}

La industria salitrera actuó como atractor, en el sentido de que fue un lugar deseado por poblaciones venidas desde Perú, Bolivia, Argentina y Chile. Dicho "atractor" fue el que hizo, por un lado, aumentar los flujos de población enganchada hacia las faenas del nitrato $y$, por otro, resistirse a aceptar las crisis salitreras de 1914, 1919 y siguientes.La economía del nitrato permitió no solo un mercado para bienes venidos desde el interior del continente y de ultramar, sino, adicionalmente, la construcción en el desierto de una sociedad dinámica y con identidad, bajo el concepto de "pampina". Posiblemente, esta identidad fue el principal "atractor" para enganchados y voluntarios que se movilizaron hacia el desierto del Norte Grande de Chile durante el ciclo de expansión de nitrato.

Durante el siglo diecinueve y hasta el primer tercio del siglo veinte, la industria del salitre estaba estrechamente vinculada, social y comercialmente, con zonas ubicadas al oriente de los Andes, tanto el altiplano y valles de Bolivia como el noroeste de Argentina (Conti 2006). También los circuitos de bienes y personas desde y hacia las salitreras alcanzaron las provincias peruanas de Tacna y Tarata desde inicios del ciclo del nitrato en Tarapacá (Rosenblitt 2010), cuyas consecuencias se sintieron hasta su fin y con relación al conflicto entre Perú y Chile por esas provincias (Skuban 2005).

En este sentido, como adelantamos, el ciclo del nitrato chileno se asemeja más al ciclo argentífero, dinamizado a partir del cerro rico de Potosí, descrito y analizado por Carlos Sempat Assadourian, cuya explicación se transformaría en un modelo para la minería — basado en la teoría de los polos de crecimiento de Perroux- que, según Sempat, erróneamente se calificó de "enclave" (1982: 279).

El autor describe de este modo lo denominó "el sistema de la economía colonial":"...

Para realizar el análisis concreto tomaremos como ejemplo el espacio colonial peruano del siglo XVII. La elección del espacio $y$ del periodo tiene sus razones, sobre todo porque muestran un movimiento de vaivén; punto de llegada de un proceso, originado en el siglo anterior, de formación de un mercado a un nivel de macroescala regional; punto de arranque de su desintegración al llegar a un nivel crítico las contradicciones internas, a las cuales se suma la presión directa de ciertos países europeos en una etapa avanzada de desarrollo capitalista. También por encontrarse allí formas económicas y sociales que sorprenden por su larga duración y cuyos residuos aún pueden detectarse en el presente. Queremos creer, asimismo, si no es demasiado aventurado, que esta forma de análisis puede significar otra perspectiva distinta para comprender el proceso de creación y configuración de los estados nacionales que surgen en el siglo XIX..." (Sempat 1982: 110).

Efectivamente, este espacio colonial precedió a la conformación de los Estados nacionales, los que una vez consolidados, desarticularon definitivamente ese espacio colonial al establecer fronteras político administrativas para controlar los flujos de bienes y personas - a nivel de macro escala-, que hasta entonces lo hacían respondiendo a un mercado tradicional, por un lado, y a un emergente mercado capitalista, por otro. Sin embargo, en el territorio del Norte Grande de Chile post Guerra del Pacífico, con fronteras en transición, el proceso de desarticulación del espacio colonial se vio retrasado hasta que dichas fronteras quedaran establecidas por medio de tratados internacionales.En la medida en que los Estados nacionales 
de Perú, Bolivia, Argentina y Chile comenzaron a definir sus fronteras, el espacio transfronterizo salitrero, que hasta entonces había sido notoriamente poroso, comenzó a perder relevancia. Este fenómeno coincide con el término definitivo del ciclo de expansión del salitre: el Tratado de Paz y Amistad entre Perú y Chile se suscribe en 1929, el mismo año cuando se inicia la crisis asociada a la Gran Depresión internacional (Monteón 1998).

Uno de los primeros estudiosos que relaciona la economía minera del Norte Grande de Chile con la política vecinal es Francisco Zapata. Este autor plantea que las relaciones internacionales contemporáneas entre Bolivia, Perú y Chile "pueden definirse en el contexto de la crisis del mercado de las materias primas minerales" (1992: 17). Por lo tanto, la política vecinal de los tres países "está inserta en la dinámica del mercado de las materias primas minerales" (1992: 17). De tal modo, pasa revista a esas relaciones bilaterales desde los siglos XIX y XX y su relación con el desierto de Atacama, el que podría convertirse en una plataforma o núcleo de desarrollo para los tres países.

El Norte Grande de Chile, como es entendido e imaginado en la actualidad, fue, en definitiva, el resultado de tres fenómenos - económico, diplomático y social- que se dieron en paralelo, a veces en forma complementaria y en otras en forma contradictoria: la industria del salitre, la diplomacia estatal y la sociedad en el desierto. La industria generó la actividad necesaria para la circulación de mercancías y el poblamiento del desierto, que la diplomacia permitió hasta 1904, cuando se definen las fronteras internacionales.

Aquí sostenemos que la política salitrera chilena, después de ocupado todo el territorio de explotación de este recurso como resultado de la Guerra del Pacífico, fue clave para la estructuración de un hinterland transfronterizo en torno a la industria del nitrato, donde los nexos o encadenamientos alcanzaron regiones del centro y sur de Chile, las provincias de Arica, Tacna y Tarata, y regiones transandinas de Bolivia y Argentina, especialmente Cochabamba y el noroeste, respectivamente. Este hinterland le proporcionó a la industria salitrera trabajadores, mercancías tradicionales, insumos para la industria, animales para las faenas y para el consumo, etc. En este trabajo nos centraremos específicamente en el vínculo trasandino entre la industria del salitre y algunas regiones de Boli- via, enmarcadas en las relaciones diplomáticas bilaterales entre ambos países.

\section{La importancia del impuesto}

Chile se enfrentó, en 1880 - cuando debió administrar políticamente todo el territorio donde estaba ubicada la industria del nitrato de soda-, a un dilema: continuar la política salitrera peruana (que inició el presidente $\mathrm{Ma}$ nuel Pardo a través de la expropiación de esta industria, con la idea de, posteriormente, transferirla a capitalistas nacionales), o aplicar un impuesto alto a la exportación y dejar que esta industria se desenvolviera según la conducta de los empresarios. La decisión que resolvería el dilema tendría consecuencias fundamentales, no solo para esta industria y para la economía de Chile, sino también para la región salitrera y sus nexos regionales transfronterizos.

Es sabido que el Estado nación chileno optó por el impuesto alto, tomando una posición que podría calificarse de rentista (Castro 2005), expresada de forma muy gráfica en la famosa frase del presidente Domingo Santa María: "no importa que se lo lleven barato (empresarios extranjeros), eso es a cuenta, yo los espero a la salida, y ahí me pagan el saldo" (Huidobro 1926: 496). Esta frase expresa algo más que una opción por el capital extranjero; también, implícitamente, dejó en sus manos la administración económica de un territorio.

El camino para llegar a esa decisión se inició el 12 de septiembre de 1879 (ley $\mathrm{N}^{\circ}$ 750), con la aplicación de un impuesto de cuarenta centavos (40 ctv.) por quintal métrico; luego, el 3 de enero de 1880, se constituyó la Comisión Consultiva para estudiar el problema salitrero de Tarapacá. Fue esta comisión la que sugirió la aplicación de un impuesto alto que compensara el beneficio de dejar en manos de los salitreros esta industria. Hubo diversos proyectos al respecto, algunos proponían valores específicos por cantidad de salitre, otros un porcentaje sobre la renta, etc. El 2 octubre de 1880, se promulgó la ley $\mathrm{N}^{\circ}$ 1.060, que estableció un derecho de exportación de un peso y sesenta centavos fuertes $(\$ 1,60)$ o su equivalente en papel de curso legal, por cada cien kilogramos de salitre. La región de Taltal tuvo un trato diferenciado; a partir del 15 de enero de 1882 (ley $\mathrm{N}^{\circ} 1.435$ ) solo pagaba un $50 \%$ del impuesto que grava al salitre según la ley 
$N^{\circ} 1.060$ (Campaña 1900: 195).

Francisco Valdés Vergara, quien fuera hacia 1884 jefe político de Tarapacá, describe de este modo la aplicación del impuesto en el mes de octubre de 1880: "...fecha en que, por haberse normalizado ya los negocios en Tarapacá con el alejamiento de las operaciones militares, se creyó más ventajoso dejar la producción del salitre entregada a la lei de la libre competencia i fijar un derecho de exportación que asegurara a Chile los beneficios que en su calidad de ocupante bélico le correspondían..." (1884: 5).

Este impuesto no será temporal, sino que acompañará a la industria del salitre hasta su declinación con el término de la Primera Guerra Mundial, cuando comenzará a cuestionarse su eficacia: "La Semana del Salitre recomienda la siguiente conclusión: es necesario estudiar un cambio del derecho salitrero que grave al producto en una suma relacionada con la ley del caliche explotado en tal forma que la participación del Estado mantenga su relación actual" (Brieba 1926: 523). Aunque todavía hacia 1926 había quienes defendían ese impuesto que había generado altos ingresos a Chile: "Esos derechos son prudentes. No han sido alzados desde su establecimiento, hace más de cuarenta y cinco años, ni durante la guerra mundial, en que cualquier otro país lo habría hecho (...) Tales derechos son en realidad bastante menores que al principio, por el menor valor adquisitivo del oro en el transcurso de medio siglo..." (Silva 1926: 482). Resulta sorprendente la estabilidad de este impuesto, a pesar que especialistas venían cuestionando la tributación salitrera desde una década antes, especialmente porque el salitre había perdido competitividad. Hacia 1918, el salitre representaba solo "el 40\% de la producción mundial de azoe" (Bertrand 1919: 11). Cuando se estableció el impuesto, el único competidor relevante del nitrato de soda era el sulfato de amoniaco. En cambio, al término de la Primera Guerra Mundial eran muchos los competidores, y uno particularmente fuerte: el salitre sintético.

Entre 1880 y 1919, el impuesto salitrero no se caracterizó por incentivar la libre competencia sino, más bien, la colusión (González 2014b), pero generó importantes ingresos al Fisco, que cuestionan el carácter rentista de esta economía. Este beneficio llevó al Estado nación chileno a intervenir mínimamente en la región salitrera; incluso compartimos el concepto de Luis Castro, respecto al campo de la educación pública como un "Estado ausente o distante" (Castro 2008), política pública clave para entender la libertad de acción que tuvo el empresariado salitrero para vincular esa industria con regiones allende los Andes, sin que la frontera fuera un obstáculo.

Esta ausencia estatal, que entendemos como una decisión política - además, en concomitancia con la acción diplomática, como veremos más adelante-, facilitó una libre circulación de bienes y personas en todo el territorio salitrero desde Pisagua hasta Taltal y sus conexiones con otras regiones de Chile, y también con regiones transfronterizas de Bolivia y Argentina. Respecto de las regiones del Perú, las vinculaciones más importantes se realizaron con Tacna y Tarata que, en la época, estaban bajo ocupación chilena.

Este trabajo intenta demostrar la existencia de un espacio de influencia de la industria salitrera al amparo de la política económica y política exterior de Chile, iniciadas durante el gobierno del presidente Domingo Santa María, que se desarrolló entre el occidente de Bolivia, el noroeste argentino y el Norte Grande de Chile.

\section{La importancia de las fronteras en transición}

La política exterior de Chile durante el gobierno del presidente Domingo Santa María se caracterizó por lo que algunos autores han denominado "la política boliviana" (Concha 2007), basada en el esfuerzo de la diplomacia chilena por aproximarse a Bolivia, en la búsqueda de un equilibrio de poder regional respecto de Perú y de Argentina. Esta política tuvo altibajos durante su vigencia, pero tendrá como resultados un Pacto de Tregua en 1884 y un Tratado de Paz y Amistad en 1904, mientras los Pactos de mayo de 1895 fueron un fracaso (Concha 2011: 102).

El Estado nación chileno tuvo que, de facto, establecer los límites de la provincia de Tarapacás, principal región fronteriza con Bolivia, aunque no existiera un tratado de límites con ese país. Tarapacá tuvo por límite con Bolivia a los tradicionales hitos reconocidos durante el período peruano, siguiendo a geógrafos de esa nacionalidad

\footnotetext{
5 "Lei que crea la provincia de Tarapacá". Diario Oficial de la República de Chile $N^{\circ}$ 2261, 31 de octubre 1884, Santiago de Chile.

6 Zapaleri.
} 
como Mariano Paz Soldán (1878). Fue con el Pacto de Tregua de 1884 cuando se estableció una frontera entre ambos países; en el artículo $2^{\circ}$ se señala que la línea de los territorios ocupados por Chile tienen por:

"límite oriental una línea recta que parta de Sapalegui ${ }^{6}$, desde la intersección con el deslinde que los separa de la República de Argentina, hasta el volcán Licancaur. Desde este punto seguirá una recta a la cumbre del volcán apagado Cabana. De aquí continuará otra recta hasta el ojo de agua que se halla más al sur en el lago Ascotán; y de aquí otra recta que, cruzando a lo largo de dicho lago, termine en el volcán Ollagua?. Desde este punto otra recta al volcán Túa, continuando después la divisoria existente entre el departamento de Tarapacá y Bolivia..." (Aldunate 1907: 223).

Si bien este pacto considera la presencia de una comisión de ingenieros frente a alguna dificultad de interpretación, claramente esta frontera quedó sin delimitarse hasta 1906, cuando los peritos de ambos países establecieron en terreno los hitos fronterizos (Risopatrón 1910). En definitiva, la frontera entre Bolivia y Chile entre 1879 y 1904 estuvo en transición, es decir, bajo un litigio diplomático que debía resolverse con un tratado definitivo de límites. Mientras ello no aconteciera, los Estados nacionales evitaron establecer controles fronterizos a la circulación de bienes y personas, beneficiando notoriamente a la economía minera, en general, y salitrera, en particular. En otras palabras, en ese período, y hasta las dos décadas siguientes, se trató de una frontera porosa.

Según José Miguel Concha, a la "política boliviana" se le "atribuye un periodo que va desde 1879 a 1900 (incluso hay autores que señalan 1904 como fecha de su término) tendrá un periodo de vida más breve que el ya señalado, que iría desde 1879 a 1899" (2007: 32). Sin embargo, es difícil comprender que esta política de acercamiento entre ambos países haya concluido antes de firmado el Tratado de 1904, considerando los términos del acuerdo donde notoriamente se privilegia la integración física entre ambos países a través de ferrocarriles. Después del Tratado de 1904, recién hacia 1910 un autor boliviano atento al litigio con Chile, como Jorge Escobari Cusicanqui, identifica una acción diplomática que demanda acceso a un territorio en el litoral del Pacífico: "El 22 de abril de 1910, el Canciller de Bolivia Daniel Sánchez Bustamante, diri-

7 Ollagüe. gió un Memorándum a las Cancillerías de Chile y Perú, en el que luego de manifestarles que Tacna y Arica para Bolivia tienen importancia efectiva por su dependencia geográfica y comercial..." (1978: 30). Aquí, Bolivia se distancia tanto de Chile como de Perú en su búsqueda del puerto de Arica, lo que sepulta definitivamente toda "política boliviana" desde la Cancillería chilena, pero ello no significa necesariamente una "política peruana", menos cuando se encuentran en el gobierno del Perú Augusto B. Leguía y su canciller, Melitón Porras. El año 1910 será, también, clave en la política interna chilena, bajo el clima del centenario de la república, donde surgen pensamientos críticos, entre ellos, un pensamiento nacionalista y un cuestionamiento al Estado nación (Pinedo 2011), que en cierta forma influirá en las relaciones fronterizas.

Bolivia presentará el mismo argumento de 1910 el 14 de enero de 1919 ante la Liga de las Naciones, aprovechando el clima político generado tras el término de la Primera Guerra Mundial (Brissot 1919). Más allá del resultado de esta demanda, sostenemos que este fue el punto de inflexión entre ambos Estados nacionales, que marcaría las relaciones diplomáticas hasta la actualidad.

De todas formas, la distensión entre Bolivia y Chile se prolongó más allá de 1904, hasta que los ferrocarriles dejaron de ser la piedra de toque del desarrollo, lo que coincide aproximadamente con el término de la construcción del ferrocarril entre Arica y La Paz en 1913, obra incluida en el Tratado de Paz y Amistad de 1904.

\section{La importancia de los ferrocarriles y los empresa- rios mineros}

¿Por qué los ferrocarriles? Desde la perspectiva de la economía salitrera, con ellos era más eficiente la traída de enganches de trabajadores desde Bolivia y la importación de bienes de consumo (p. ej. harinas, carnes, tejidos, lanas, chichas, hoja de coca, etc.) y de insumos básicos para la industria minera (mulares, carretas, correas, ganado bovino y ovino, ropa industrial como polainas, fajas, zapatones, etc.). Esta política no benefició solamente a la industria salitrera, sino también a la del cobre y del bórax, entre otras. En dirección contraria, la existencia de fronteras abiertas facilitó la reexpedición de productos modernos (cocinas y planchas de fierro, planchas o calaminas de zinc, té, leche condensada, telas de casimir, 
sombreros, etc.), que ingresaron por los puertos de embarque hacia esas regiones transfronterizas del sur del Perú, occidente de Bolivia, noroeste de Argentina, y de Chile. Esta circulación de bienes y personas integró un espacio transfronterizo y generó un mercado eficiente para las diversas actividades mineras del Norte Grande de Chile, especialmente para la industria del nitrato. En otro trabajo hemos revisado las aduanillas de Oruro, donde se señala con detalles la circulación de mercancías en este territorio trasandino (González 2013b).

Gustavo Rodríguez Ostria, uno de los más versados especialistas en el mercado interno y externo boliviano en los siglos XIX y XX, nos dice que:

"A principios de este siglo (s. XX) el gobierno boliviano, contaba con abundantes fondos provenientes de las indemnizaciones otorgadas por Chile y Brasil en compensación de la enajenación de sus territorios de la costa del Pacífico y el Acre respectivamente, había decidido ejecutar una ambiciosa politica de construcción ferroviaria. En el imaginario de las elites la línea férrea era emisaria de civilización, unidad nacional y acceso preferente al mercado; tenerla a su disposición era por consiguiente casi la única posibilidad, a su entender, de conjugar los fetiches de la tradición e ingresar con paso firme a la modernidad. Negársela equivalía a excluirla de los fastos del progreso y la modernización, condenándola a permanecer recluida en el "localismo" y el deleznable pasado" (1995: 22).

Habría que agregar a esa observación que esa elite era esencialmente minera. También, que esa perspectiva modernizadora no era exclusiva de elite boliviana, sino que ya venía consolidándose desde el siglo anterior en toda América, a tal punto que se estaba pensando, a comienzos del siglo veinte, en un ferrocarril continental que uniera Buenos Aires y Washington. El ferrocarril sería la columna vertebral de la integración americana, y Bolivia, el corazón del continente.

Esta política ferroviaria fue impulsada preferentemente por el presidente boliviano que firmó el Tratado de 1904, Ismael Montes:

"Politica Ferroviaria.

La obra iniciada en el primer periodo presidencial del exemo señor Ismael Montes, en cuanto ha sido y es llevada a cabo paciente y tesoneramente con voluntad firme al terreno de las realidades.

El Jefe de la Nación ha desenvuelto en un lapso de tiempo máso menos breve una política ferroviaria atinada y verdaderamente progresista desenvolviendo un vasto plano que vincula a Bolivia por el Norte con el Perú por Mollendo; al Oeste con Chile por Arica; al sudeste con el mismo país por Antofagasta, al Sur con la Argentina por la Quiaca y al extremo Norte le une con el Brasil por el ferrocarril Madera Mamoré.

(...) La acción del gobierno ha sido y es bien orientada desde hace diez años a esta parte, y este vigoroso empuje va dando los resultados fructiferos tanto tiempo acariciados; a despecho de politicos pesimistas y de espíritus superficiales y poco analíticos atacados de esa obsesión enfermiza que cierra los ojos a toda obra de progreso. El presidente Señor Montes ha satisfecho la aspiración nacional..." ${ }^{8}$.

En 1913, Chile concluye el ferrocarril de Arica a La Paz, posiblemente fue la última señal simbólica de la integración política entre Bolivia y Chile (y Perú) a través de un sistema ferroviario. Según el historiador boliviano Juan Albarracín, refiriéndose a un viaje de Ismael Montes por Buenos Aires, Lima y Santiago:

“... en Santiago de Chile Montes propuso sin ambajes, la cesión de Arica a Bolivia como solución al problema del Pacífico y también como base de una paz definitiva y unión de Bolivia con Chile y Perú. Insistiendo sobre este tema, -la unión boliviano-chilenaperuana-, dirá unos días más tarde, con ocasión de la inauguración del Ferrocarril Arica-La Paz el 11 de mayo de 1913: "Abrigo la esperanza de que podremos llegar a establecer una confederación sudamericana" (1972: 194).

Este imaginario ferroviario se esfumó finalmente, y con él, la confederación trinacional, pues el mismo Ismael Montes, en 1919, ya no vería como suficientes los ferrocarriles para un acceso al litoral por parte de Bolivia; lo veremos ese año como ministro de su país en París, a cargo de la demanda en contra de Chile en la Liga de las Naciones.

El control de la frontera de la circulación de mercancías

8 Diario La Nación, 30 de Noviembre de 1916. Archivo Nacional de Sucre, Bolivia. 
comenzó a incrementarse en la medida que el ciclo del salitre transcurría y perdía relevancia económica, coincidente con la consolidación de los Estados nacionales en el territorio del Norte Grande. Veamos un ejemplo de esa preocupación por un mayor control de flujos de mercancías tradicionales desde Bolivia y Argentina, que hasta 1904 había sido un circuito conocido y aceptado sin restricciones.

“Tarapacá, Junio 5, 1913.

\section{Señor Intendente.}

Por haberse retirado la guardia de la frontera por Economía del supremo Gobierno. Cual el suscrito aplaude, se ha vuelto internar una cantidad ganado ovejuno, y me es dadle a preguntar a Usia, si es permitido o no tal Importación, pues para que el Gobierno no desembolsa Dinero sin utilidad, me permito aquí, hacerle una esposición como se podía parar, esta Internación de Ovejas

I.- Podría vender ganado lanar, en las Oficinas a pueblos sin el respectivo Comprobante, autorizado por la Subdelegación - "si son criados en la región de Chile o si vienen de Bolivia o Arjentina."- El Subdelegado por medio de los Inspectores de la Distritos, debe estar informado, cada vez que baja una manada de ganado de la cordillera, como los pasos son conocidos, seria mui facil de vigilar estos puntos y sobre todo siempre tienen que frecuentar las quebradas por los pastos.

II.- las principales Entradas son Pica-Tarapacá-y Camiña, y por consiguiente no da mucho trabajo a los subdelegados de saber si son o no aquí criados.

III.- La policía en los pueblos y oficinas confiscará todo ganado, que no viene con estos requisitos.

Por las expuesto Usía vera que con buenas voluntad y poco trabajo be ahora al Estado una gran cantidad de Dinero sobre todo si los Encargados obran con honradezy patriotismo en su despacho.

\section{Dios guie a Uds." .}

En la época estudiada, la región trasandina entre el Norte Grande de Chile y el occidente de Bolivia está definida por los ferrocarriles, la minería y la diplomacia. Los empresarios mineros, para asegurar sus intereses económicos, trabajaron en sociedades transnacionales, donde bolivianos y chilenos se asociaron para explotar el de- sierto de Atacama. Posiblemente ellos, ocupando cargos diplomáticos, fueron los que acercaron las posiciones de sus respectivos países para los acuerdos bilaterales entre 1880 y 1904.

Veamos solo a modo de ejemplo, el caso notorio de la Compañía Minera Huanchaca, "fundada en Chile en 1875, por los chilenos Melchor Concha y Toro, Juan Francisco Rivas y los bolivianos Aniceto Arce y Francisco Argandoña" (Peñaranda 1996: 3). Desde el punto de vista de la minería salitrera, hubo un territorio privilegiado donde coincidieron empresarios mineros bolivianos y chilenos: el cantón Toco. Allí, antes que el gobierno boliviano licitara en 1876 estos mantos calichales ubicados al sur de Quillagua y al poniente del río Loa —donde Cobija era el puerto de referencia para el denuncio de los cateos, aunque nunca funcionó como puerto salitrero ${ }^{10}$-, se dieron cita mineros como Ruperto Álvarez García, Enrique Zanelli, Guillermo Gamboni, Francisco Ojeda, Eulogio Alcalde, Felipe Iturriche, Onofre Aramayo, Zoilo Flores, Pedro López Gama, Francisco Manterola, Eduardo Lamartine, José Videla, Otto Harnecker, entre otros. Bolivianos, chilenos y de otras nacionalidades. Los capitales bolivianos y chilenos desaparecieron del Toco después de la Guerra del Pacífico.

No puede resultar extraña esa relación entre empresariado minero y diplomacia a fines del siglo diecinueve e inicios del veinte, entre dos países mineros y con litigios diplomáticos pendientes, precisamente respecto de un territorio donde se ubicaban importantes recursos minerales como es el desierto de Atacama. Será el Tratado de Paz y Amistad entre Bolivia y Chile el que iniciará el término de esa relación entre minería y diplomacia hasta 1919, cuando el litigio por la reivindicación portuaria boliviana se canalice exclusivamente a través de la diplomacia.

Un apellido sintetiza esos tres tópicos en ese período: Aramayo.

La dinastía de los Aramayo se inicia con José Avelino

9 Fuente: Archivo de Intendencia de Tarapacá (ITAR). Número de Ficha: 56; Libro: Subdelegaciones; Fecha de documentos: 1913; Ubicación y Código: ITAR 883.

10 Cuando efectivamente este cantón inicia su exportación después de la Guerra del Pacífico, lo hará por el puerto de Tocopilla. 
Aramayo Oballe, minero boliviano que tuvo la primera iniciativa empresarial de unir el altiplano con el litoral a través de un ferrocarril, y también con él comienza esa relación entre minería y diplomacia. El historiador boliviano Juan Albarracín señala que "durante el siglo XIX, y a partir de entonces, Bolivia no dejó de estar presente enviando sucesivamente a destacadas personalidades políticas e industriales" (1972: 19). Londres era la city, el centro más importante del mundo y la economía extractiva (minería y caucho) fue la base de su relación con Bolivia. Siguiendo a Albarracín, "en 1864 Avelino Aramayo era enviado en calidad de Agente Oficial del gobierno boliviano 'para buscar por todos los medios que estén a su alcance, los empresarios que puedan realizar el Proyecto de una nueva vía fluvial y terrestre de comunicaciones entre Bolivia y el Océano Pacífico y para llamar una Comisión Científica Exploradora'" (1972: 19). El año 1864 fue precisamente también cuando, junto al ingeniero alemán Hugo Reck, proyectaron un ferrocarril entre Tarapacá y Bolivia, por cierto, con el propósito de poder movilizar la producción minera. La presencia de Aramayo en Londres no fue inútil, pues Luis Gómez Zubieta precisa que el 1 de junio de 1864 lograría un empréstito con la firma inglesa The London County Bankun por un monto de 1.500.000 libras esterlinas para la realización de este proyecto (Gómez 1998: 367).

Luego, su hijo Félix Avelino Vega tendrá un papel diplomático clave para alcanzar Bolivia un acuerdo con Chile que llevaría a la firma del Tratado de Paz y Amistad de 1904. Francisco Encina la denomina "la misión Aramayo"; en 1902, Aramayo habría entregado una minuta al gobierno de Chile como base para un acuerdo, donde el tercer punto indicaba: "abono por parte de Chile de una suma de dinero, entregada por anualidades, destinada a la construcción de ferrocarriles que den fácil salida al Pacífico a los productos de Bolivia" (Encina 1963: 251). Ya sabíamos de la importancia que le otorgaba su padre, José Avelino, a un ferrocarril entre Bolivia y la costa del Pacífico. Estos diplomáticos - que también eran empresarios - no podían sino adscribirse a una visión del desarrollo asociada a los ferrocarriles y a la minería. Lo mismo acontecía en Perú y en Chile.

Félix Avelino Aramayo pavimentó el camino hacia el Tratado de 1904 y también influyó, con su perspectiva desarrollista adquirida en su permanencia en Europa, sobre la importancia de este acuerdo para el futuro de Bolivia sobre la base de una plataforma de comunicaciones terrestres y fluviales. Jaime Peñaranda nos dice que la familia Aramayo de los Chichas fue "gran impulsora de la utilización de capitales extranjeros y modernas tecnologías en la industria minera boliviana" (1996: 3).Félix, además, fue padre de Carlos Víctor Aramayo Zeballos ${ }^{11}$, quien tendrá un papel diplomático relevante en la demanda boliviana en contra de Chile ante la Liga de las Naciones en 1920 (Gumucio 2004: 114). Orlando Capriles afirma que:

"al comenzar la era del estaño, Carlos V. Aramayo formó en el sur del país en 1907, la Aramayo, Francke y Cia. Ltd., con una inversión, en los tres años siguientes, de más de 700 mil libras esterlinas. Fuera de las minas de Chorolque, Chocaya, Tasna, etc., que recibió en herencia, la empresa trabajó en Salala, Coltani, y otras, extrayendo plata, estaño, cobre, bismuto, antimonio, wolfran, plomo. La Compañia Aramayo-Francke y Arturo Fricke, también explotaron wólfram en la mina Chicote en Inquisivi..." (1977: 124).

La Compañía Aramayo-Francke estuvo relacionada con la famosa mina de estaño del cerro Llallagua, que posteriormente fue de propiedad de Simon I. Patiño, donde también participaron capitales chilenos. Roberto Querejazu Calvo dice que "el capital chileno se introdujo en varios distritos mineros de Bolivia y echó los ojos a la zona más rica de estaño" (1998: 85). Por cierto, se refiere a Llallagua. Esta presencia chilena en Llallagua se concretó en 1906, es decir, solo a dos años del Tratado de Paz y Amistad, y veintisiete desde que el presidente Daza "congeló los bienes de chilenos existentes en Bolivia, intervino las minas de Corocoro y ordenó la incautación de las acciones de 'Huanchaca' que no pertenecían a nacionales bolivianos" (1981: 221).

Carlos V. Aramayo, al igual que el ex presidente Ismael Montes, hacia 1919 había cambiado su posición y la de sus antepasados respecto del espíritu del Tratado de 1904, y sus beneficios, a través de los ferrocarriles en dirección hacia los puertos del Pacífico.

11 Carlos Víctor Aramayo "llegó al mundo en París y estudió en Oxford, Inglaterra” (Capriles 1977: 124). 
Al igual que los Aramayo, hubo muchos otros mineros diplomáticos en Bolivia que tuvieron algún papel en las relaciones con Chile y, a su vez, también hubo mineros diplomáticos chilenos que fueron protagonistas en la "política boliviana" iniciada bajo el gobierno del presidente Domingo Santa María, que concluyó con el Tratado de 1904, como fue el caso de Agustín Edwards.

Agustín Edwards Mac Clure tenía un perfil similar al de Félix Avelino Aramayo, pues su abuelo y su padre también hicieron fortuna en la minería. Patricio Bermedo y Eduardo Arriagada nos dicen que, entre los intereses que heredó Edwards Mac Clure, "se contaban participaciones mayoritarias en empresas como la Sociedad Industrial Atacama, la Sociedad Minera Emma Luisa, la Compañía Chilena de Seguros, el Ferrocarril de Coquimbo, el Ferrocarril de Copiapó, la Compañía Sudamericana de Vapores y la Compañía de Salitre de Antofagasta" (Bermedo et al. 2002: 14). Su abuelo, Agustín Edwards Ossandón, fue socio principal de la Compañía de Salitres y Ferrocarril de Antofagasta, la empresa salitrera que le dio sentido al litigio entre Bolivia y Chile previo a la Guerra del Pacífico.

Agustín Edwards Mac Clure fue también un diplomático muy relevante, canciller en el proceso de negociación del Tratado de $1904^{12}$, hacia el centenario de la república le correspondió reorganizar la cancillería, representó a Chile ante la Liga de las Naciones y fue el plenipotenciario chileno ante la Comisión Plebiscitaria norteamericana respecto del litigio con Perú por las provincias de Tacna y Arica.

Un (supuesto) encuentro entre Carlos Víctor Aramayo y Agustín Edwards lo relata Jorge Gumucio a través de un diálogo:

"Manifestó (Edwards) que era una locura que Bolivia pretendiera Antofagasta, pues esta ciudad era una obra de los chilenos, estaba en ese momento poblada por chilenos y éstos jamás aceptarían su transferencia a Bolivia. Remarcó que, en los altos círculos de opinión en Chile, un numeroso grupo de hombres influyentes $y$ de prestigio buscaban con sinceridad satisfacer las aspiraciones bolivianas, incluyéndose él mismo en ese grupo. Aramayo le replicó que los bolivianos tendrían que 'olvidar la historia del siglo pasado para desvanecer el sentimiento de agravio y de rencor que seguía agitando el corazón del pueblo boliviano' con relación a

\section{Chile" (Gumucio 2004: 117).}

En 1919, los mineros diplomáticos de Bolivia y Chile se distancian definitivamente, quizás porque se enfrentaba tanto una crisis diplomática como una económica.

Fue tan grave la crisis salitrera de 1919 y 1920 que la expatriación de los trabajadores bolivianos generó un problema diplomático que se resolvió prontamente, como lo menciona el diario boliviano El Norte, del 12 de febrero de 1919:

"Respecto a la publicación que hicimos de que los trabajadores bolivianos de las salitreras habian sido hostilizados, durante las agitaciones populares últimamente ocurridas en el norte de Chile, hemos recibido la carta de rectificación del señor Luis Arteaga, encargado de negocios de la vecina república, que transcribimos a continuación (...)

La Paz, febrero 11 de 1919. Señor director del diario EL NORTE. Presente.

Señor de toda mi consideración:

Con sorpresa he leído en un artículo editorial de EL NORTE de hoy, sobre la repatriación de trabajadores de las salitreras, que gran cantidad de obreros bolivianos se han repatriado de las pampas salitreras tanto por la paralización de los trabajos en las oficinas 'cuanto por la hostilidad que contra todos los obreros que no eran chilenos se inició últimamente'.

No es efectivo que los trabajadores bolivianos hayan sido en ningún momento hostilizados en Chile; por el contrario, son allíbien estimados y prueba tan fehaciente de ello es lo que expresa el ex cónsul de Bolivia en Antofagasta, señor Manuel Soria Galvarro, en una entrevista que se le hizo por 'El Diario' y que se publica en el número de hoy.

La palabra oficial de los Cónsules de Bolivia en Iquique y en Arica, podrá corroborar lo que dejo expuesto.

12 El 24 de diciembre de 1903, junto a su par boliviano, Claudio Pinilla, suscribieron un acta preliminar del contenido del Tratado de Paz, Amistad y Comercio, que posteriormente firmarían el 20 de octubre de 1904 el ministro de Relaciones Exteriores de Chile, Emilio Bello Codesido, y el plenipotenciario boliviano, Alberto Gutiérrez. 
Como prueba de la consideración que han merecido los trabajadores bolivianos que han quedado sin ocupación a causa del paro en las oficinas salitreras debo consignar que gran parte de esos trabajadores han sido repatriados de Arica hasta La Paz por el Ferrocarril de esta vía, por cuenta del Gobierno de Chile (...).

La alta sensibilidad diplomática por la demanda boliviana ante la Liga de las Naciones — situación que en la crisis de 1914 pudo considerarse menor- ahora requería de explicación a nivel diplomático. Incluso se llegó hasta la parodia, con la llamada "guerra de don Ladislao", que demostraba el ánimo de la época ${ }^{13}$. El escritor chileno Luis Enrique Délano señala, en 1973, que el año 1920 fue trascendental para Chile, porque se articulan en un solo fenómeno las consecuencias ideológicas de la revolución rusa, las económicas del término de la Primera Guerra Mundial por la crisis del salitre, y la violencia política. Sin embargo, olvida este autor que, producto de las relaciones transfronterizas del Norte Grande de Chile con Bolivia, también en ese país el año 1920 fue de crisis salitrera.

\section{Auge y caída del espacio minero transfronterizo y trasandino, 1880-1929}

Entre 1880, año en que se fija el impuesto al salitre, y 1906, año de la instalación en terreno de los hitos fronterizos entre Bolivia y Chile, surgió un espacio transfronterizo, trasandino, integrado, abierto y con un mercado de bienes y personas autosustentable, debido a que las políticas chilenas - minera y exterior- se complementaron o imbricaron para facilitar el tránsito de mercancías y personas desde y hacia los centros mineros ubicados en el desierto de Atacama. Sin embargo, después de 1904, este espacio comienza a ser afectado por la crisis minera y por la crisis diplomática. Como I. Wallerstein plantea, la crisis capitalista es "una circunstancia rara, la circunstancia en que un sistema histórico ha evolucionado hasta el punto que el efecto acumulativo de sus contradicciones internas impide que el sistema resuelva sus propios dilemas por medio de ajustes en sus patrones institucionales vigentes" (2007: 146). Es decir, comienza a perder fuerza

13 Se refiere a un llamado a la movilización del ejército hacia el norte de Chile, en base a información secreta que supuestamente poseía el ministro de Guerra, Ladislao Errázuriz Lazcano, ante una inminente guerra con Perú y Bolivia. y, en consecuencia, deja que - en este caso estudiadoel Estado nación tenga el predominio de las decisiones respecto del territorio y sus fronteras. Por lo mismo, después del Tratado de Paz y Amistad de 1904 entre Bolivia y Chile, las crisis económicas y los litigios diplomáticos son causas de un lento proceso de desintegración del espacio transfronterizo, hasta que en 1929, luego de la firma del Tratado de Paz y Amistad entre Perú y Chile, emerge en su ordenamiento territorial definitivo el Norte Grande de Chile.

Entendemos por "fronteras en transición" en el Norte Grande de Chile al proceso durante el cual las diplomacias desarrollaron las negociaciones para la firma de los tratados bilaterales y su posterior ejecución de la definición de las fronteras internacionales (fueron especialmente relevantes para la emergencia de las "fronteras en transición" el Tratado de Ancón entre Perú y Chile y el Pacto de Tregua entre Bolivia y Chile, ambos de la misma época). Durante este proceso, existió una "tensión fronteriza" debido a la incertidumbre del resultado y, desde la industria minera, una oportunidad para ampliar sus zonas de influencia transfronterizas en pos de lograr una economía regional autosuficiente y espacialmente integrada.

Con la ejecución del Tratado de Paz y Amistad de 1904 entre Bolivia y Chile se inició un proceso de definición de las fronteras, disminuyendo la "tensión fronteriza" y desapareciendo el carácter "transicional" de las mismas. Sostenemos que, a partir de este momento, se inicia un lento proceso de desintegración del "espacio minero transfronterizo" hasta concluir, hacia 1929, con una nueva geopolítica de las fronteras. Del mismo modo, el territorio conocido como Norte Grande de Chile termina por estructurarse, tomando las características geográficas y políticas conocidas hasta la actualidad.

Por su parte, la frontera con Perú - que era de facto en el río Sama mientras se esperaba el resultado del plebiscito establecido por el Tratado de Ancón- permitió que las provincias de Tarata y Tacna se integraran sin restricciones al mercado minero chileno, hasta 1925 y 1929 , respectivamente.

En 1904 se inició el lento proceso de desintegración del espacio minero transfronterizo, donde la industria sali- 
trera fue la plataforma pivotal (Boisier 1994) económica y social principal. Dicha desintegración fue producto de un doble proceso: uno, los litigios diplomáticos y posterior amojonamiento de las fronteras, y dos, las recurrentes crisis salitreras, cada vez más profundas (1904, 1910, 1913-14, 1919-20, 1929-34) (González 2014).

Lo anterior implicó: 1. Recurrentes movimientos obligados de personas a través de las fronteras, producto de las crisis económicas; 2. Fronteras que desaparecen (p. ej. Tarata desaparece como zona de frontera en 1925, Camarones y Sama lo hacen 1929) y otras que surgen (la línea de la Concordia no era frontera y emerge como tal en 1929); 3. Surgen las triples fronteras de Ancomarca y Zapaleri, con las consecuentes tensiones en las comunidades andinas, donde algunas son divididas por la frontera internacional (Pisiga en 1906, Ancomarca en 1929, etc.); 4. Mayor control fronterizo del "contrabando" de bienes que habían circulado sin restricciones, y un aumento de las rondas policiales hasta la aparición de los primeros puestos fronterizos hacia 1927, pero además comienzan a surgir mayores conflictos en la frontera internacional, ya no referidos a incursiones de campesinos y pastores aymaras, como fue lo tradicional a partir de 1906 (González 2009, Castro 2014), sino incursiones de militares. Veamos a modo de ejemplo la siguiente carta del ministro de Relaciones Exteriores, Conrado Ríos Gallardo, al gobernador de Pisagua, a quien le correspondía la subdelegación donde se ubica la zona fronteriza de Isluga-Pisiga:"

Iquique 6 de Agosto de 1929.-

\section{Al Señor}

Gobernador del departamento de Pisagua.-

En respuesta al oficio $N^{\circ} 235$ de 21 de Junio último, con que US. tuvo a bien formular denuncio sobre incursiones de Carabineros bolivianos a territorio chileno en un peso de cordillera entre Isluga y Pampa de Parajalla, cúmpleme transcribir a US. las instrucciones enviadas a la Legación en la Paz, que son del tenor siguiente:

Acompaño a US. los antecedentes de un denuncio hecho ante de las autoridades de Tarapacá, y que la Intendencia de esta provincia ha elevado al Ministerio de mi cargo, sobre violaciones de nuestra frontera por tropa armada de policía de Bolivia, seguidas de atropellosy despojos a ciudadanos chilenos.- Sirvase US. llevar estos hechos en forma amistosa, a conocimiento de ese Gobierno, para la correspondiente investigación y a fin de que en lo sucesivo se eviten estos incidentes que perturban las buenas relaciones de ambos países.- Después de una prolija indagatoria, US. hará presente que si la autoridad Boliviana confirma los hechos reclamados, procedería la devolución de las especies y valores indebidamente expropiados.-

Tan pronto dicha Legación comunique al Ministerio de mi cargo el resultado de sus gestiones, lo pondré en conocimiento de US.Dios guie a US. Conrado Ríos Gallardo.-" 14 .

Este hecho debe ser entendido en el contexto del inminente acuerdo entre Perú y Chile, que tuvo por resultado el Tratado de Paz y Amistad entre ambos países, lo que la República de Bolivia pudo considerar lesivo para sus intereses. De todos modos, es una demostración de que esa zona fronteriza ya no podía ser circulada por flujos de mercancías y trabajadores, como en la décadas anteriores. En el estado central, ya desde el fracaso boliviano ante la Liga de las Naciones de su demanda por el puerto de Arica, se observó un clima diferente en Bolivia respecto de su relación bilateral con Chile. Posiblemente por el golpe de estado en Bolivia, que llevó al poder al presidente Bautista Saavedra, se comenzó a discutir la necesidad de reforzar más la vigilancia sobre la frontera con Bolivia, como lo vemos en el siguiente fragmento de un documento enviado desde el gobierno a la intendencia de Tarapacá:

«Santiago, 30 de Diciembre de 1922.- $N^{\circ} 2435$ -

(...) "Se ha impuesto este Ministerio de su informe $N^{\circ} 11798$, de 11 del presente mes, recaido en el oficio reservado del Señor Ministro de Relaciones Exteriores $N^{\circ} 44$ de 29 de Noviembre último, relacionado con la necesidad de reforzar el servicio de resguardo de los distintos puntos de la Provincia de Tarapacá, fronterizos con Bolivia, que son objeto de frecuentes y perjudiciales incursiones de autoridades y particulares bolivianos.- El infrascrito estima muy atendibles las razones expuestas por Ud., referentes a la dificultades que para el resguardo del orden en algunos puntos

14 Fuente: Archivo de Intendencia de Tarapacá (ITAR), Libro: Oficios Generales, Año: 1929, Foja 27, ubicación: ITAR - 1482.

15 Archivo Intendencia de Tarapacá (ITAR); Volumen: $N^{\circ}$ 1203; Archivo: Confidenciales; Fecha del documento: 12/01/1923; Título sintético: "Sobre la necesidad de establecer vigilancia en la frontera chilena con Bolivia". 
acarrearía el establecimiento de este nuevo servicio; pero ante la necesidad de atender a esta vigilancia de la frontera oriental, expreso a Usted la conveniencia de organizar un servicio provisorio mientras puede constituirse el Escuadrón "Pisagua" propuesto por Usted".- Tan pronto esté organizado el Escuadrón provisorio que hará aquella vigilancia, tendré el agrado de comunicarlo a Usted.- Dios guarde a Usted.- Fdo.- Manuel Rivas Vicuña» ${ }^{15}$.

Es evidente cómo el conflicto diplomático comienza a expresarse en el territorio, desarticulando los circuitos transfronterizos que habían caracterizado al ciclo del salitre, sumado al hecho de que el propio ciclo ya no estaba en su fase expansiva (que concluye hacia 1919), sino en su fase de decadencia ${ }^{16}$.

La desintegración del espacio transfronterizo relacionado con las recurrentes crisis económicas y sociales se puede observar a partir del movimiento social de 1904 (Reyes 1973) y la pérdida de competitividad del nitrato chileno (Bertrand 1910), concluyendo con la depresión de 1929 (Hurtado 1984). Las crisis económicas de la minería de Atacama generaron un fenómeno de migraciones pendulares (Blanco 2012) transfronterizas, donde se destacan las migraciones cochabambinas (González 2009). Con razón el historiador cochabambino, Gustavo Rodríguez Ostria, señala que:

"[...] entre 1910-1920, por ejemplo, cuando la crisis del mercado se hacía insoportable y para colmo la sequía se tornaba también insoportable, literalmente miles de campesinos, colonos y artesanos cochabambinos se dirigieron a pie hasta las salitreras de Tarapacá y Antofagasta, en búsqueda de trabajo, renunciando a establecerse en zonas más cercanas y al alcance del sistema departamental como el Chapare. Desde alli muchos retornaban cruzando en dos largas semanas los páramos cordilleranos para el tiempo de la siembra y la cosecha, como si la cosa no fuera sino uno más de sus nichos ecológicos" (1995: 21-22).

Esta población, mayoritariamente hablante quechua, ¿interactuó al cruzar los Andes con los habitantes de las fronteras de habla aymara? No lo sabemos, pero sí quedaron sus huellas en la demografía y la cultura del Norte Grande de Chile.

Para Saskia Sassen,

"Los procesos económicos transfronterizos no son nada nuevo. Los flujos de capital, de trabajo, de bienes, de materias primas, de viajeros han existido a través de los siglos. Asimismo, ha habido enormes fluctuaciones en el grado de apertura o cierre de los cuadros organizacionales dentro de las cuales se han dado estos flujos. Durante los últimos cien años, es el sistema inter-estatal el cual ha provisto el marco organizativo dominante para los flujos transfronterizos, con los estados nacionales como actores clave" (2003: 6).

Lo que esta autora destaca, a partir de la década de 1980, es la escala de la globalización. Sin embargo, es posible identificar en el pasado histórico fenómenos específicos donde determinados territorios transfronterizos se organizaron en torno a alguna industria, articulándose y desarticulándose con ciertos grados de autosuficiencia, como fue el caso - durante la Colonia- de la explotación de la plata de Potosí y otros centros mineros, estudiado por Carlos Sempat (1982). También es posible identificar un fenómeno similar en el "espacio salitrero", pero con la presencia de los Estados nacionales que inician su proceso de consolidación de las fronteras internacionales, generando una tensión fronteriza inexistente en el "espacio peruano", acelerando o adelantando el proceso de desarticulación o desintegración de dicho espacio transfronterizo.
16 En otro trabajo, hemos discutido las inflexiones de inicio y término del ciclo de expansión del salitre (González 2014b). 


\section{$*$ Referencias citadas}

1972. El poder minero. Empresa editora Urquizo Ltda., La Paz.

ALDUNATE S. C. 1907. Leyes, decretos y documentos relativos a salitreras. Imprenta Cervantes, Santiago de Chile.

BENEDETTI, A. y E. SALIZZI. 2011. Llegar, pasar, regresar a la frontera. Aproximación al sistema de movilidad argentino-boliviano. Revista Transporte y Territorio 4: 148-179.

BERTRAND, A. 1910. La crisis salitrera. Louis Michaud Editor, París. 1919. Tributación salitrera. Estudio acerca de su mejor adaptación al mercado post-bélico. Imprenta y Litografía Universo, Santiago de Chile.

BLAKEMORE, H. 1996. Historia del Ferrocarril de Antofagasta a Bolivia 1888-1988. Edición Mercedes Gajú-Impresos Universitarios, Santiago de Chile.

BLANCO, J. P. 2012. Migraciones pendulares en la península Ibérica durante la época moderna. Notas acerca del papel de la trashumancia en la determinación del sistema migratorio de la España interior. Estudios Humanísticos Historia 11: 121-146.

BOISIER, S. 2004. Desarrollo territorial y descentralización. El desarrollo en el lugar y en las manos de la gente. Revista EURE $\operatorname{XXX}(90): 27-40$.

BREIBA, E. 1926. La tributación salitrera. En Semana del Salitre celebrada en Santiago de Chile, pp. 508-523. Academia de Ciencias Económicas, Imprenta y Litografía La Ilustración, Santiago de Chile.

BRISSOT (José Carrasco Torrico). 1919. Bolivia ante la Liga de las Naciones. Tipografía y Litografía Marinoni, La Paz.

CAPRILES, O. 1977. Historia de la minería boliviana. Litografías e Imprentas Unidas S.A., La Paz.

CASTRO, L. 2005. Regionalismo y Desarrollo Regional: Debate Público, Proyectos Económicos y Actores Locales (Tarapacá 1880-1930). Ediciones de la universidad de Valparaíso, Viña del Mar.

2008. El Estado chileno, los agentes fiscales y el temprano ordenamiento administrativo. Chungara. Revista de antropología chilena 40 (2): 219-233.

2014. La conformación de la frontera chileno-boliviana y los campesinos aymaras durante la chilenización de Tarapacá (Tarapacá, 1895-1929). Historia Crítica 52: 231-251.

CLAVAL, P. 2002. El enfoque cultural y las concepciones geográficas del espacio. Boletín de la A.G.E. 34: 21-39.

CONCHA, J. M. 2007. La Política Boliviana. Iniciativas del Ejecutivo chileno para una alianza estratégica con Bolivia (1879-1899). Brickl ediciones, Santiago de Chile.

2011. Las iniciativas chilenas para una alianza estratégica con Bolivia (1879-1899). Plural Editores, La Paz.

CONTI, V. 2002. Entre la plata y el salitre. Los mercados del Pacífico para las producciones del Norte argentino (1830-1930). En Una tierra y tres naciones. El litoral salitrero entre 1830 y 1930, (Coms.).pp 119-149. Universidad Nacional de Jujuy, San Salvador de Jujuy.

2006. La ruta de los arrieros y el salitre. En Las rutas del capricornio andino, A. (Eds.). Consejo de Monumentos Nacionales, Santiago de Chile.

DÉLANO, L. E. 1973. El año 20. Pineda Libros, Imprenta Mueller, Santiago de Chile.

ENCINA, F. 1963. Las relaciones entre Chile y Bolivia (1841-1963). Editorial Nascimento, Santiago de Chile.

ESCAMILLA, F. 1999. Las fronteras conceptuales de un debate: el significado en Norteamérica del término "Frontier". Biblio 3W Revista Bibliográfica de Geografía y Ciencias Sociales 164. En línea, disponible en: http://www.ub.edu/geocrit/b3w-164. htm.

ESCOBARI, J. 1978. Historia diplomática de Bolivia. Tomo 1․ Universidad Boliviana, La Paz.

FELLMANN VELARDE, J. 1981. Historia de Bolivia. Tomo II. La Bolivia semifeudal. Editorial Los Amigos del Libro, La Paz - Cochabamba.

GODOY, M. y S. GONZÁLEZ. 2013. Norte Chico y Norte Grande: construcción de un imaginario compartido, 1860-1930. En La sociedad del salitre. Protagonistas, migraciones, cultura urbana y espacios públicos, S. González (Comp.), pp. 195-214. RIL Editores, Santiago de Chile. 
GÓMEZ Z. L. 1998. Ferrocarriles en Bolivia del anhelo a la frustración 1860-1929. Ediciones UMSA, La Paz.

GONZÁLEZ, S. 1995. Cochabambinos de habla quechua en las salitreras de Tarapacá (1880-1930). Chungara 27 (2): 135-151.

2009. La presencia boliviana en la sociedad del salitre y la nueva definición de la frontera: auge y caída de una dinámica transfronteriza (Tarapacá 1880-1930). Chungara. Revista de antropología chilena 41 (1): 71-81.

2002. Hombres y mujeres de la pampa. Tarapacá en el ciclo de expansión del salitre. Ediciones LOM, Santiago de Chile.

2014. Las inflexiones de inicio y término del ciclo de expansión del salitre (1872-1919). Una crítica al nacionalismo metodológico. Diálogo Andino 45:39-49.

2014b. ¿Especuladores o industriosos? La política chilena y el problema de la propiedad salitrera en Tarapacá durante la década de 1880. Revista Historia 47:39-64.

2013. La sociedad del salitre. Protagonistas, migraciones, cultura urbana y espacios públicos. RIL Editores, Santiago de Chile.

2013b. ¿Espacio o territorio? La integración transfronteriza de la economía salitrera. El caso de Bolivia (1870-1920). En Fronteras en movimiento e imaginarios geográficos. La cordillera de los Andes como espacialidad socio-cultural, A. Núñez, R. Sánchez y F. Arenas (Eds.), pp. 275-306. RIL Editores, Santiago de Chile.

GONZÁLEZ PIZARRO, J. A. 2007. La imagen de Chile en la obra inédita y desconocida de Andrés Sabella (1912-1989). Historia 4O(I): 35-68.

HEVILLA, M. C. 1998. El estudio de la frontera. Una aproximación Bibliográfica, Revista Bibliográfica de Geografíay Ciencias Sociales 125. En línea, disponible en: http//www.ub.es/geocrit/b3w-125.htm.

LÓPEZ MOLINA, A. 2008 Fundamentación epistemológica de las ciencias humanas (El diálogo de Habermas con Dilthey). Anales del Seminario de Historia de la Filosofía 25: 407-426.

MAYA, O. 2005. El Norte Grande chileno en la narrativa. Panorama de literatura regional. Ed. Corporación Pro Antofagasta, Antofagasta.

Ministerio de Relaciones Exteriores de Chile. 1922. Chile y la aspiración de Bolivia a un puerto en el Pacífico. Imprenta Universitaria, Santiago de Chile.

MONTEÓN, M. 1998. Chile and the Great Depression. The Politics of Underdevelopment, 1927-1948. Center for Latin American Studies Press, Arizona State University, Tempe, AZ.
PAZ SOLDÁN, M. F. 1878. Verdaderos límites entre el Perú y Bolivia. Imprenta Liberal, Lima.

PEÑARANDA, J. 1996. ¿Who is who? en la minería boliviana. Documento de Trabajo $N^{\circ}$ 1/96, Instituto de Investigaciones Socio-económicas, IISEC, La Paz.

REYES NAVARRO, E. 1973. El desarrollo de la conciencia proletaria en Chile (el ciclo salitrero). Editorial Orbe, Santiago de Chile.

RISO-PATRÓN, L. 1910. La línea de la frontera con la república de Bolivia. Imprenta Universo, Santiago de Chile.

RODRÍGUEZ OSTRIA, G. 1995. La construcción de una región. Cochabamba y su historia. Siglos XIX y XX. Editorial de la Universidad Mayor de San Simón, Cochabamba.

ROSENBLITT, J. 2010. El comercio tacnoariqueño durante la primera década de vida republicana en Perú, 1824-1836. HISTORIA 43 (I): 79-112.

SASSEN, S. 2003. Localizando ciudades en circuitos internacionales. Revista EURE XXIX (88): 5-27.

SEMPAT, C. 1982. El sistema de la economía colonial. Mercado interno, regiones y espacio económico. Instituto de Estudios Peruanos IEP, Lima.

SILVA, A. 1926. Los derechos de exportación del salitre. En Semana del Salitre celebrada en Santiago de Chile, pp. 472-483. Academia de Ciencias Económicas, Imprenta y Litografía La Ilustración, Santiago de Chile.

SKUBAN, W. 2005. Una cuestión dentro de la cuestión. El nacionalismo y la cuestión indígena en el sur del Perú, 1900-1930. RevistaANDINA 41: 89-108.

TEJEDA, J. L. 2004. La línea, la frontera y la modernidad. Estudios Fronterizos 5 (10): 73-90.

VALDÉS VERGARA, F. 1884. La crisis salitrera y las medidas que se proponen para remediarla. Imprenta de El Progreso, Santiago de Chile.

WALLERSTEIN, I. 2007. Geopolítica y geocultura. Ensayos sobre el moderno sistema mundial. Editorial Kairós, Barcelona.

YEPES, E. 1999. Un plebiscito imposible. Tacna-Arica 1925-1926. Editorial Escuela Nueva, Lima.

ZAPATA, F. 1992. Atacama. Desierto de la discordia. El Colegio de México, México, D.F. 
El Norte Grande durante el Ciclo del Salitre: La política salitrera y la política exterior EN LA FORMACIÓN DE UN ESPACIO TRANSFRONTERIZO (BOLIVIA Y CHILE, 1880-1929)

Fuentes citadas:

Archivo de la Intendencia de Tarapacá (ITAR).

Archivo Nacional de Sucre, Bolivia.

Diario El Norte, La Paz, 1919.
Diario Oficial de Chile, 1884.

Diario La Nación, La Paz, 1916.

Extracto de entrevista al Señor Basilio Osinaga, realizada en Iquique el año 1989 (Archivo Hombres y Mujeres de la Pampa). 